\title{
Optimizing the Profit of an Agricultural Company through the Application of Genetic Algorithms
}

\author{
Rodes Angelo B. da \\ Silva \\ Doctoral Student Depart- \\ ment of Agricultural Engi- \\ neering \\ UFRPE/Recife, PE
}

\author{
Héliton Pandorfi \\ Professor of the \\ Agricultural Engineering \\ Department \\ UFRPE/Recife, PE
}

\author{
Gledson Luiz P. de \\ Almeida \\ Professor of the \\ Agricultural Engineering \\ Department \\ UFRPE/Recife, PE
}

\author{
Nicole Viana da Silva \\ Graduate Student in Agri- \\ cultural and Environmen- \\ tal Engineering \\ UFRPE/Recife, PE
}

\begin{abstract}
For the proper planning of production processes in agricultural companies, resources are needed that allow the development of methodologies capable of bringing optimal solutions that support decision making. The aim of this study was develop a prototype to optimize the profit of an agricultural company through the application of genetic algorithms. Obtaining data regarding production processes belong to a dairy company specialized in the manufacture of dairy products, located in the municipality of Caruaru, state of Pernambuco. An on-site visit was carried out to survey the entire production process of the products under study; interview with the business owner to learn about their main market interests; collection of data for the elaboration of a business model, with emphasis on product diversification and improvement in the company's profit margin. From the data, an "AG planning" prototype was developed using the python language and the tkinter library. For the implementation, the objective based function was first developed. in profits and 10 restrictions were modeled based on manufacturing time of each product, number of employees and hours worked. Three repetitions of 3,6 and 10 executions of the algorithm were performed to verify the highest possible profit value. The most significant increase in the profit margin was identified infirst simulation with 3 runs. With the using genetic algorithms it was possible to plan the weekly production of the company.
\end{abstract}

\section{Keywords}

Animal production, optimization, artificial intelligence

\section{INTRODUCTION}

In recent decades the milk production chain in Brazil has undergone important transformations technological[2]. Brazil, the development of agriculture has limited resources added to competition in the foreign market and the lack of a stable agricultural policy. In this context, the proper planning of activities in the properties it is essential, having as principle the application of methodologies that will bring optimal solutions for the your Law Suit productive[9].

Thus small dairies find it difficult to stay on the market, because they depend on resources for investment and The your production can be affected by climatic factors, which makes it difficult to manage the raw material. In this context, the use of Operational Research with these companies can be considered a tool to support decision making andproduction control, both for small dairies and large industries [13].

According to [8] agricultural planning is the main instrument for the rural producer to achieve the established objectives. Martin (1994) mentioned that the production cost constitutes important information in the decision process and that esti- mating this cost became simpler as the adoption of information technology in the management of agricultural companies increased. [11] presented a study for the optimization of agricultural properties in the Tarai region, in Nepal, aiming to increase the profit in properties of 1.5 and 5 ha. [8] created a computerized system with the objective of assisting rural business administrators in the planning phase of agricultural activities. This system sought to maximize profit from activities suitable for cultivation during the agricultural year.

Linear programming problems are widely applied in the fields of organization and economic management companies, using as a methodology data from them in relation to the restrictions where are formulated like math functions for application.

Os genetic algorithms are a class of algorithms that has been increasingly useds at resolution of these problems. They are characterized by being stochastic search algorithms that have development and functioning trailers to genetics, in which all new species are produced through natural selection in which the fittest survives generating offspring [10][4].

In the programming area, similar problems can be solved using linear programming methods from the modeling of the objective function with linear behavior. Using a set of constraints, in the form of mathematical equalities or inequalities, can be limited to region of possible values to be calculated by the objective function. After The modeling this function tends to be maximized or minimized by some kind of algorithm [1][7].

The aim of this study was develop a prototype to optimize the profit of an agricultural company through the application of genetic algorithms.

\section{RELATED WORK}

The study was carried out indairy company specialized in the manufacture of dairy products, located in the municipality of Caruaru, state of Pernambuco. Wanting to know what products this dairy should produce to make the biggest profit possibleand thus be able to expand your production respecting the restrictions of input and working hours.

The company has been producing some dairy products: coalho cheese, mozzarella cheese, parmesan cheese, yogurt, cream cheese, long-life milk, butter and dulce de leche. This choice was due to the fact that even being products where there is a great equality of raw material, their financial return is unequal. The production of each of the products under study requires time, labor and ingredients for its processing, which are also called manufacturing resources.

To determine a method where the optimal production plan of 
this little dairy industry employed to following methodology: on-site visit for a better view of the entire production process of the products under study; interview with the company owner seeking to know their main market interests; data collection and elaboration of a proposed model that uses, Given this situation, one can question how to prepare a production plan without changes in the company's portfolio, and respecting at your limitations and themarket, also generating the best financial result for the company. Therefore, the company under study wants to establish a weekly schedule for the production of eight types of dairy products: coalho cheese (4 $\mathrm{kg}$ packaging), mozzarella cheese (5 kg packaging), Parmesan cheese (4 kg packaging), yoghurt (package of $0.9 \mathrm{~kg}$ ), cream cheese (package of $0.18 \mathrm{~kg}$ ), long-life milk (package of $1 \mathrm{~kg}$ ), butter (package of $3.2 \mathrm{~kg}$ ) and dulce de leche (package of $0.5 \mathrm{~kg}$ ).

The objective function was written based on profits per unit presented by the products produced in the dairy:

through the best product mix, to maximize the company's profit, employing the concepts of operational research applied to linear programming.

$$
Z=3 \times 1+5 \times 2+5 \times 3+x 4+x 5+2 \times 6+2 \times 7+2 \times 8
$$

On what:

$$
\begin{aligned}
& \mathrm{x} 1=\text { rennet cheese } \\
& \mathrm{x} 2=\text { mozzarella cheese } \\
& \mathrm{x} 3=\text { Parmesan cheese } \\
& \mathrm{x} 4=\text { yogurt } \\
& \mathrm{x} 5=\text { curd } \\
& \mathrm{x} 6=\text { long life milk } \\
& \mathrm{x} 7=\text { butter } \\
& \mathrm{x} 8=\text { dulce de leche }
\end{aligned}
$$

10 constraints were modeled based on nthe production capacity from the company according to the table below (table 1).

Table 1. Agricultural company economic and production data

\begin{tabular}{|c|c|c|c|}
\hline Product & $\begin{array}{c}\text { Current demand } \\
\text { (units) }\end{array}$ & Forecast (units) & $\begin{array}{c}\text { Average production } \\
\text { time (hours) }\end{array}$ \\
\hline curd cheese & 80 & 100 & 24 \\
\hline Mozzarella cheese & 80 & 100 & 9 \\
\hline Parmesan cheese & 50 & 100 & 8 \\
\hline Yogurt & 200 & 150 & 4 \\
\hline Cream cheese & 100 & 150 & 5 \\
\hline long life milk & 200 & 250 & 20 \\
\hline Butte & 90 & 100 & 0.5 \\
\hline Milk cream & 150 & 200 & 8 \\
\hline
\end{tabular}

Considering the time each product takes to be produced in hours and the fact that the company has 10 employees working 8 hours a day, which is equivalent to 400 hours a week, the following restriction must be respected:

$24 \times 1+9 \times 2+8 \times 3+4 \times 4+5 \times 5+20 \times 6+0.5 \times 7+8 \times 8>400$

(maximum number of working hours)

$\mathrm{x} 1>100$

$$
\begin{aligned}
& x 2>100 \\
& x 3>100 \\
& x 4>150 \\
& x 5>150 \\
& x 6>250 \\
& x 7>100 \\
& x 8>200
\end{aligned}
$$

$\mathrm{x} 1, \mathrm{x} 2, \mathrm{x} 3, \mathrm{x} 4, \mathrm{x} 5, \mathrm{x} 6, \mathrm{x} 7, \mathrm{x} 8>0$

The necessary parameters for the application of genetic algorithms in solving the proposed problem (figure 1).

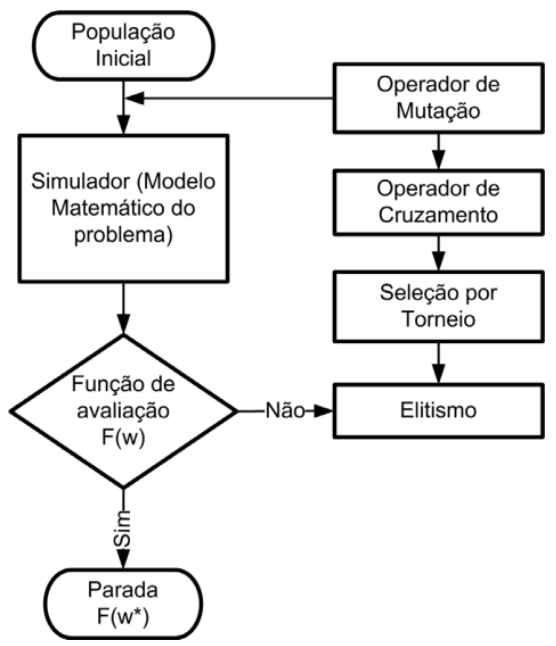

Figure 1.- Flowchart of solving optimization problems with genetic algorithms

Each of the genes will be assigned a specific corresponding letter.

$\mathrm{x} 1=$ chromosome $(0)$
$\mathrm{x} 2=$ chromosome $(1)$
$\mathrm{x} 3=$ chromosome $(2)$
$\mathrm{x} 4=$ chromosome $(3)$
$\mathrm{x} 5=$ chromosome $(4)$
$\mathrm{x} 6=$ chromosome $(5)$
$\mathrm{x} 7=$ chromosome $(6)$
$\mathrm{x} 8=$ chromosome $(7)$

The influence of genetic parameters on the performance of the algorithm depends on the class of problems being dealt with. Thus, the designation of an optimized set of values for these parameters will depend on the performance of several tests.

Initial tests show that the implemented GA converges more quickly adopting an initial population of at least 30 individuals. The maximum population size was set at 100 individuals, as values greater than that make the AG slow and did not produce better results. A mutation rate of $0.5 \%$ according to the literature was also used.

The assessment ("Fitness") checks if the chromosome 
represents a good solution. The evaluation function is the objective function represented by equation 1 . The 10 constraints of the model were used to verify whether the proposed solution is contained in the space of search.

Took place 3 successive repetitions of 3, 6 and 10 executions to verify the functioning of the algorithm and the maximum values of the profits obtained by it (table two). The genetic parameters were configured as follows: number of individuals in the initial population $=30$, mutation rate $=0.15 \%$, maximum number of static generations $=1.000$. We chose to use an elitism value equal to zero, as the algorithm normally converged to this solution.

These values were stipulated for the genetic parameters after the execution of preliminary tests. The quoted values make the AG converge for the best results.

\section{RESULTS AND DISCUSSION}

Often the volume of information processed through the AGs is high, making the manual process unfeasible. Thus, a software prototype was developed for thesolving the profit optimization problem of an agricultural property using genetic algorithms. For this, the Python language, the Tkinter library, which allows the development of graphical interfaces in the Python IDLE environment, was used.

The interface of the "AG Planning" prototype developed is shown in Figure 3. Figure 4 shows the basic flowchart of the "AG Planning" prototype.

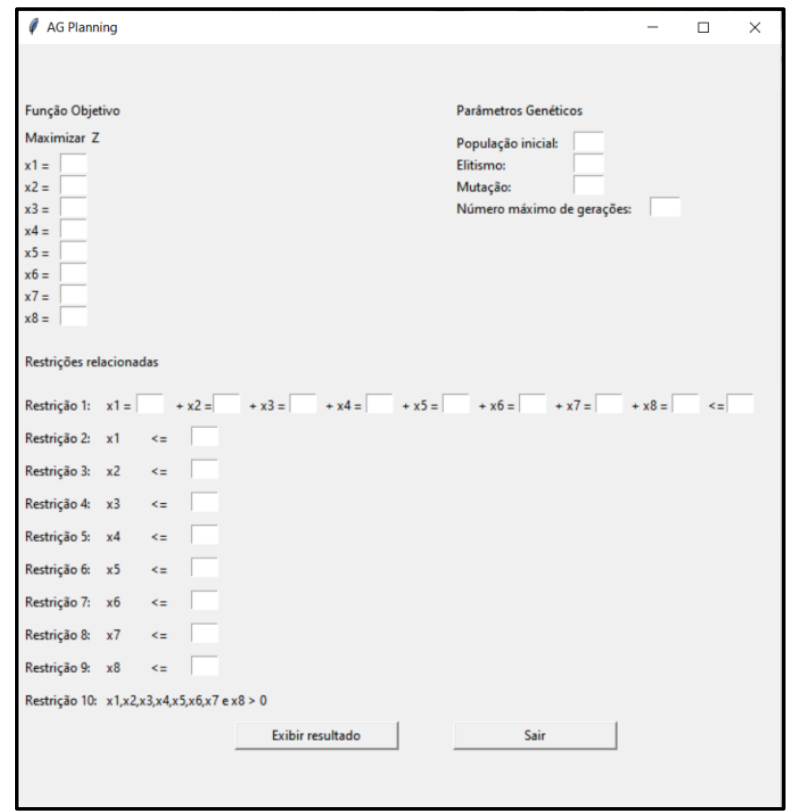

Figure 3. Software prototype interface "AG Planning"

The results referring to the genetic algorithm implemented with a population of 30 individuals are shown in table 2 . The values refer to the units of the products that should be produced by the company with the aim of obtaining maximum weekly profit. As for the number of individuals in the population, higher values were not used because the algorithm took a long time to converge. With these values, the algorithm took around 20 seconds to converge to a solution.

During executions, at some point the algorithm failed to converge to a solution. These runs were filled with the value zero in table 2.
Table 2. Values referring to units of products to be produced weekly referring to the three repetitions in which the algorithm runs

\begin{tabular}{|c|c|c|c|c|c|c|c|c|c|}
\hline $\begin{array}{c}\text { curd } \\
\text { deese }\end{array}$ & $\begin{array}{c}\text { Cheese } \\
\text { rennet }\end{array}$ & $\begin{array}{c}\text { Cheese } \\
\text { Parmesan }\end{array}$ & Ioghurt & Rcheese & $\begin{array}{c}\text { longlife } \\
\text { milk }\end{array}$ & $\begin{array}{c}\text { Mold } \\
\text { woman }\end{array}$ & $\begin{array}{c}\text { Milk } \\
\text { cream }\end{array}$ & $\begin{array}{c}\text { Profit } \\
\text { (BRL) }\end{array}$ \\
\hline 1 & 3 & 13 & 1 & 1 & 1 & 95 & 191 & 659 \\
\hline 1 & 7 & 5 & 3 & two & 1 & 96 & 189 & 640 \\
\hline 1 & 1 & 5 & 1 & 1 & two & 99 & 191 & 619 \\
\hline \multicolumn{7}{|c|}{ Repetition 2 } \\
\hline 1 & 11 & 5 & 1 & 1 & 1 & 99 & 190 & 665 \\
\hline 1 & 1 & 14 & 1 & 1 & 1 & 95 & 197 & 666 \\
\hline 1 & 20 & 9 & 1 & 1 & 1 & 95 & 127 & 596 \\
\hline 4 & two & two & 1 & 1 & 1 & 90 & 183 & 582 \\
\hline 1 & 5 & 14 & 1 & 1 & two & 100 & 127 & 558 \\
\hline 1 & 3 & 13 & 1 & 1 & 1 & 95 & 191 & 659 \\
\hline \multicolumn{7}{|c|}{$|c| c|c| c|c| c|c| c \mid$} \\
\hline 1 & 10 & 6 & 1 & 1 & 1 & 100 & 190 & 667 \\
\hline two & 1 & 10 & 1 & 1 & 1 & 95 & 191 & 637 \\
\hline 1 & 4 & 15 & two & 1 & two & 95 & 125 & 545 \\
\hline 1 & 5 & 14 & 1 & 1 & two & 99 & 127 & 556 \\
\hline 0 & 0 & 0 & 0 & 0 & 0 & 0 & 0 & 0 \\
\hline 1 & 10 & 14 & 1 & 8 & 1 & 95 & 123 & 570 \\
\hline 1 & 7 & $?$ & 1 & 1 & 1 & 95 & 200 & 667 \\
\hline 0 & 0 & 0 & 0 & 0 & 0 & 0 & 0 & 0 \\
\hline 1 & 6 & 7 & 4 & 1 & 1 & 100 & 191 & 657 \\
\hline two & 4 & 7 & 1 & 1 & 1 & 99 & 191 & 645 \\
\hline
\end{tabular}

In this way, the fitness of the individual is defined as the best solutions that present the highest profit values for the company from the objective function. Through Graph 1 we can visualize these values generated through the simulation with the proposed algorithm

The best profit value for the 3-run simulation was BRL 659.00 , for the simulation with 6 executions $\mathrm{R} \$ 666.00$ and for the simulation with 10 executions the best profit was BRL 667.00. Optimum profit was obtained for a larger number of runs.
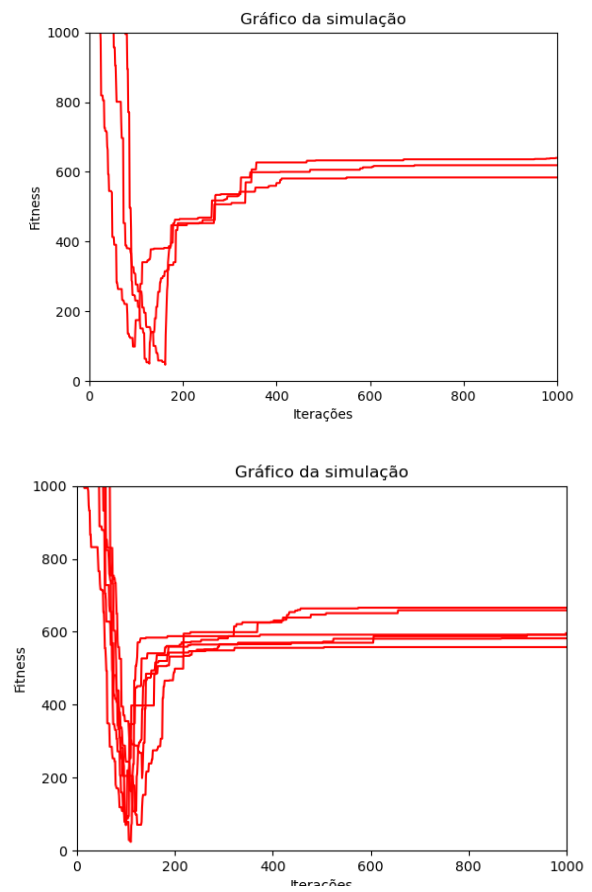


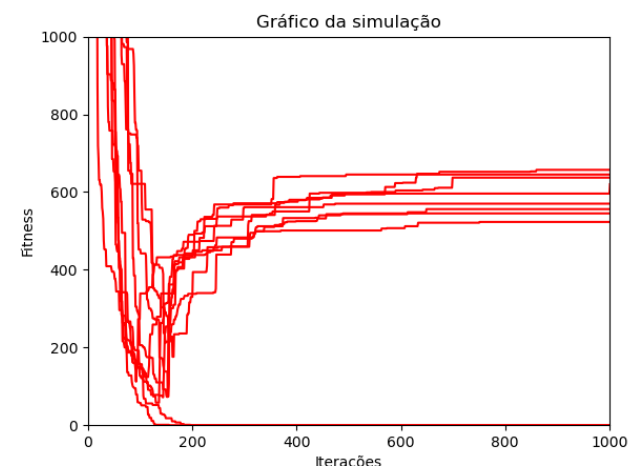

Graph 1. Fitness of the best individual of the generation for the simulation 1 with 3 runs (A), for simulation 2 with 6 runs (B) and for simulation 3 with 10 runs $(C)$.

[10] used the technique of genetic algorithms in decision making in the production planning of a dairy cooperative and got The from first iteration with the initial population, composed of 30 randomly generated individuals, with unit profits variesram from $\$ 598.5$ to $\$ 700$, and the twenty-first iteration, final population, after convergence, with the 30 individuals reaching the monetary value of $\$ 708$ for the manufactured products. [12] used a alternative method using genetic algorithm to optimize the profit of an agricultural property. The results obtained by the proposed method ranged between $\mathrm{R} \$ 32,756.91$ and $\mathrm{R} \$ 34,387.08$ against a profit of $\mathrm{R} \$ 31,377.64$ without using the AG.

\section{CONCLUSION}

The results can be considered good since the objective of this work was fully achieved, that is, with the use of genetic algorithms it was possible to plan the weekly production of the company.

Genetic Algorithms proved to be an efficient tool in the optimization of complex problems, such as in the case of optimization-related problems, in addition to not requiring any special properties on the objective function, such as derivability, for example.

The solution of this problem using the MS_Excel 2007 Solver tool, does not make its solution unfeasible with the application of genetic algorithms, since the latter is more general, indicated, also, in the solution of problems.

\section{REFERENCES}

[1] Cormem,T.H., Leiserson, C.E., Rivest, R.L. and Stein, C. 2002. Algorithms: theory and practice (2. ed.). Rio de Janeiro.
[2] Embrapa. 2020..Applications of Infrared Thermography (TIV) in beef cattle. Available at: <https://ainfo.cnptia.embrapa.br/digital/bitstream/item/21 4175/1/DOC-276-Final-em-Alta.pdf $>$ Accessed on $12 / 24 / 2020$

[3] Goldbarg, M.C. and Pacca, H.L.L. 2000. Combinatorial Optimization and Linear Programming: Models and Algorithms. Rio de Janeiro: Editora Campus.

[4] Holland, J.H 1975.Adaptation in natural and artificial systems. Ann Arbor: University of Michigan Press.

[5] Linden, R. 2008. Genetic algorithms: an important tool of computational intelligence. 2nd ed. RiverinJanuary: EditoraBrasportLivros e Multimídia Ltda.

[6] Martin, N.B. Costs: agricultural production cost system. Inf. Economic., São Paulo, vol. 24, no. 9, p. 97-122, 1994

[7] Moreira, D.A. Administration of production and operations. São Paulo: Cengage Learning, 2008.

[8] Oliveira, A.J .An intelligent decision support system for planning rural businesses. 1995. Dissertation (Masters) Federal University of Viçosa, Viçosa, 1995.

[9] Ribeiro, R. And Fortes, B. 2015.Linear programming: A contribution to the management of a rural property. XXXV National Meeting of Production Engineering (ENEGEP), Fortaleza-CE

[10] Rodrigues, W.O.P., Reis Neto, J. F. and Souza, C.C. 2012. Genetic Algorithms as a Decision Support Tool in Dairy Production Planning. Capital Scientific Magazine - Electronic (RCCe), 10.

[11] Salokhe, V.M. and Pariyar, M.P. 1990. Optimum farm planning by linear programming for Tarai belt of Nepal. Agricultural Mechanization in Asia, Afrik and Latin America, Tokyo, 21(4):76-81.

[12] Santa Catarina, A.,Opazo, B.A.D. and Bach, S.L.2002.Use of a genetic algorithm to optimize the profit of an agricultural property, Acta ScientiarumMaringá, . 24(5): 1473-1480,

[13] Stacanelli, T.M., Moura, R.A.,Silva, Y.V.B.,Silva, G., Da Silva, A.M. 2015. Application of linear programming to optimize production in a dairy located in the mid-west region of minas gerais. XXXV National Meeting of Production Engineering.

[14] Viana, G.V.R. 1998. Metaheuristics and scheduleparallel in combinatorial optimization. Fortaleza: EUFC. 